was applied promptly to the trunk of the common carotid artery, with the effect of checking the bæmorrhage; and a consultation was held between Staff-Surgeon Grahame and Assistant-Surgeons Inman and Keelan, when it was determined to tie the right common carotid (the pressure apon which had never been relaxed). This was accordingly done by Dr. Grahame just above the omo-hyoid, the wound in the neck being brought together by three points of interrupted wire suture. The hæmorrhage was completely arrested. The amount of blood lost immediately before the operation was betreen thirty and forty ounces. The patient bore it well, and his pulse (which had almost disappeared at the wrist) became more full and regular (120). Noon: Slept quietly since the operation. -7 P.M.: Coughed ap a little dark-coloured clotted blood, apparently derived from diseased lungs. A knob of ice to be placed occasionally in the mouth; draught of hydrochlorate of morphia at bedtime; the diet to consist of fowl, beef-tea, milk, and two eggs.

Dec. 8th.-Had a good night, and has just woke up much refreshed. Pulse 120, regular, more firm than yesterday. Repeat the draught.

9th.-A good deal of gnawing pain in the right side of the head. Pulse 104, full and firm ; face cheerful ; appetite good; bowels opened freely this evening. To continue the draught.

11th.-10 A.Mr.: Has just woke up from a sound sleep. Some discharge of pus from the lower part of the wound in the neck; sutures removed, and water-dressing applied; both jugulars pulsating. Stethoscope reveals the presence of tricuspid regurgitation. Repeat the draught.

12th. - Slight hæmoptysis (about half an ounce) of dark clotted blood coughed up. The right ear full of thick, yellow, healthy-looking pus. To continue the draught

13th.-Sleeps well. Edges of the wound in the neck uniting kindly. Pulse 92 ; tongue clean; bowels opened freely by enema. To have fish instead of fowl. Repeat the draught.

15th.-Going on well ; pulse 96 ; eats his food with relish; strength evidently improving. Night draught discontinued. 18th.- Slept well (without draught); is tired of his fish. To have mutton chop instead.

20th.-Ligature looks longer; patient doing well in every way; pulse 96.

23rd.-Going on in every way satisfactorily.

26th.-There is a whitish slough on the anterior surface of a polypoid excrescence, which appears to do duty for uvula and velum pendulum.

29th.-Ligature found lying loose in wound; removed it; wound in neck nearly healed. The patient is very comfort. able, and has gained much strength.

The satisfactory progress, so far, of this case is peculiarly gratifying when the many circumstances tending to militate against its success are taken into consideration-viz., first, the originally cachectic condition of the patient; second, the necessity for continual digital pressure on the trunk of the vessel, thus diminishing the space for operative measures; third, the unavoidable period of operation (by candle-light) ; and, fourth, the prostrated condition of the patient from loss of blood.

A CASE OF

INDUCTION OF PREMATURE LABOUR BY MEANS OF THE UTERINE DOUCHE.

BY MARK LONG, M.D.

SURGBOY TO OUT-PATIENTS AT THE POPLAB HOSPITAI.

THE following case of induction of premature labour by means of the uterine douche may perhaps be worth publishing, in connexion with that recorded by Dr. Poole in The Lancer of the 18th June last, in which Dr. Barnes's bags were used.

The subject of the operation, Mrs. H-, at the present time aged thirty years, was delivered by me, in Nov. 1868, of her first child by craniotomy, after having endeavoured unsuccessfully, and after employing all allowable force, to effect delivery by the long forceps. The contraction of the pelvis which rendered the performance of craniotomy necessary was at the brim, and was due to the approximation of the horizontal rami of the pubes behind the symphysis, by which the antero-posterior diameter was diminished, but to so slight a degree that I had considerable hope that the labour would be terminated by the aid of the forceps; in this, however, I was disappointed, as the forceps, although applied for more than an hour, did not advance the position of the head, and perforation had therefore to be resorted to. As the child was not a very large one, I advised my patient, before I ceased attendance upon her, to have labour brought on artificially at the seventh month, should she ever again become pregnant.

She accordingly consulted me when she was about six months advanced in pregnancy; and on the 14th June, at 3 P.M., a fortnight more than seven months after she last menstruated, I passed an elastic tube about three or four inches within the os uteri, external to the membranes, and injected about a pint of warm water in a gentle stream, from which the patient did not experience the least pain or uneasiness. No pains came on that day, but she felt some "bearing-down" sensations, which continued also the following day. At 3 A.M. on the 16th June I was called, and found strong expulsive pains recurring every three or four minutes. On examination per vaginam, I found the os completely dilated, with the head presenting, and the membranes, which were very tough, low in the vagina. I therefore ruptured them, and the pains increased in rapidity and strength for about an hour without causing any advance in the position of the head, so that I began to think I should have to apply the forceps; but just then some progress was made, and the labour was terminated in about half an hour by the birth of a living female child, the placenta coming away in the usual manner. Since then the mother has made an uninterruptedly good recovery, and the child is doing well.

This is one of those cases in which the contraction of the pelvis is just sufficient to make it necessary to resort to the fatal perforation of the child's head if it be of or above the average size, and in which the induction of labour before the full time is of such great advantage, and usually followed by such satisfactory results; for it enables a woman, who otherwise, as in this case, would be debarred from ever having a living child, and would be exposed to all the suffering and danger attending the operation of craniotomy whenever she became pregnant, to bear a family with only the ustal amount of pain, and with little if any additional risk.

The ease with which the uterine douche can be applied, and the efficacy with which it acted in this case, will form strong inducements to my repeating its use, should I again have occasion to induce premature labour.

Barking-road, Essex, August, 1870.

\section{TWO CASES OF STRANGULATED HERNIA REDUCED BY THE APPLICATION} OF COLD WATER.

\section{BY PHILIP FOSTER, M.D.}

THE complete success of the very simple treatment employed in the two following cases induces me to forward a report of them for publication. Although cold has been long employed in the reduction of strangulated hernia, still the application of it in this form is, as far as I am aware at least, a novelty, and possesses the great recommendations of extreme simplicity, and the means of carrying it out being always at hand.

In the first case (Mr. W-) the hernia, a large oblique inguinal one, had been strangulated for sixteen hours, was extremely painful and tender to the touch, and attended with great nausea and vomiting.

In the second case (Mr. S- the hernia, a small femoral one, had been strangulated for about ten hours, was but slightly painful, and unattended with nausea or vomiting.

In both cases the patients were advanced in life (about sixty), and the hernia had existed in a reducible form for several years. After trying the taxis patiently for about half an hour in each case without producing the slightest effect, I applied cold water. In Mr. W-'s case the tumour disappeared in about ten minutes under the influence of the 
cold water alone; in Mr. S_-_'s case, after about the same length of time, the reduction was effected almost immediately upon removing the cold water cloth and reapplying the taxis. The patients were placed in the position usually recommended, and the cold water was applied by means of a pocket-handkerchief, the application being renewed every two or three minutes.

One word as to the rationale of this treatment. I believe that the cold water does not act simply by diminishing the contents of the sac, but that it has also a stimulating effect upon the muscular coat of the intestine, causing movement in it, and thus promoting reduction. And in this respect I think it not improbable that cold water may be preferable to ice, the latter having a depressing rather than a stimulating effect, especially where the vital tone of the intestine has been lowered by long strangulation.

Leeds, August, 1870.

\section{a ifthror}

\section{OF THE PRACTICE OF}

\section{MEDICINE AND SURGERY IN THF}

\section{HOSPITALS OF LONDON.}

Nulla autem est alia pro certo noscendi via, nisi quamplurimas et morborum et dissectionum historias, tum aliorum, tum proprias collectas habere, et inter se comparare.-Morgagri De Sed. et Caus. MLorb., lib. iv. Procmium,

\section{G U Y'S H O S P T A L. \\ CASE OF NEPHROTOMY.}

(Under the care of Dr. Moxon and Mr. BRYsNT.)

IN the "Mirror" of July 2nd we have already referred to this case, and we now proceed to relate its further history, with an account of the post-mortem examination.

On admission the man presented some sub-conjunctival codema, and some fulness of the left loin; and on examination his urine was found to contain pus unmixed with mucus. Mr. Bryant performed the operation of nephrotomy on the 27th of June last. No calculus was discovered, but a few ounces of pus were evacuated through the wound. The following particulars are gathered from elaborate notes by Mr. Gillingham:-

On the following day, fourteen ounces of urine, in which a few pus-cells were detected under the microscope, were passed by the natural passage. On the second day after the operation twenty-four ounces were passed, in which a few pus-cells were again detected, and the dressings of the wound were free from any urinary smell; the abdomen was a little tender and slightly tympanitic. On the third day the patient passed forty-four ounces of urine, free from both pus and albumen; the abdomen was still slightly tender, but the general health seemed good; and, the wound looking healthy, the sutures were removed. During the two following days there was neither abdominal tenderness nor any other unfavourable symptoms. But on the sixth the tenderness returned. On the night of the eighth turpentine stupes were applied to the abdomen. On the ninth fluctuation was detected at the lower portion of the abdomen. On the tenth day the patient suffered from the distension of the abdomen and bilious vomiting, but was relieved by the renewed application of turpentine stupes and the administration of opium; the bowels were freely open. The symptoms then abated for a time; but on the twentyfourth day the patient was again taken with bilious vomiting and increased abdominal tenderness and distension, the skin became cold and clammy and covered with perspiration, coffee-ground vomiting continued during the night, and death ensued at one o'clock on the following morning.

Ever since the operation the patient had been free from pain in the loins; and the discharge from the wound, carefully examined by Dr. Stevenson, had revealed no urinary constituents.

At the post-mortem examination both pleuræ were found to be adherent inferiorly; on the left side the pleura was also adherent to the diaphragm, and the diaphragm, by means of adventitious fibrous tissue, to the kidney. The lower portion of the left lung was the seat of chronic pneumonia, and its tissue was so wasted that the great vessels approached close to the surface, while the relics of lung. tissue which surrounded them were pervaded by fibrous bundles. The heart was healthy, but the pericardium contained about five ounces of subinflammatory effusion. The peritoneum was everywhere thickened by chronic inflammation, and was also universally in a state of acute inflam. mation; it contained a large quantity of opalescent fluid, with flakes and shreds of lymph. The great vessels and tissues in front of the spine were thickened into a dense resisting œdematous and white fibrous mass, by which also the pancreas, duodenum, spleen, descending colon and left kidney were rigidly fixed. Some such condition, involving sympathetic centres, had been suspected, on account of an amount of tympanites disproportionate with the other symptoms. The liver, also, was adherent to its bed, and, by means of a thickened gall-bladder, to the transverse colon. The hepatic tissue was coarse, but otherwise healthy. The spleen and supra-renal capsules were healthy. The right kidney weighed nine ounces and a half, and though its elementary structure seemed coarse, it was otherwise perfectly healthy. So also was the corresponding ureter, and the bladder as well, with the exception of two small ulcers situated near the thickened orifice of the left ureter, which was thickened and ulcerated throughout. Its channel was completely interrupted by a tubercular swelling of its coats, an inch below the pelvis of the kidney. The renal pelvis was not much enlarged, but thickened and eroded by shallow ulcers. The calyces were increased by the disappearance of the pyramids and by ulcerations in their site. Thus were formed large cups lined with pyogenic membrane, forming cavities in lumps of caseous matter of about the size of $a$ plum, corresponding to the original fetal lobules. The whole cavity so formed would have contained from six to seven ounces of pus. Mr. Bryant's incision had entered the back of the pelvis of the kidney; but the passage had nearly closed towards the surface of the wound, which was in a healing state.

The examination showed that no harm had been done to the patient by the operation, which very much relieved his sufferings; and, further, that the left kidney could have been removed. The right kidney and the bladder were healthy, and quite in a state to carry on the functions of the urinary system.

\section{WESTMINSTER HOSPITAL.}

CASE OF MALIGNANT DISEASE OF LEFT SUPERIOR MAXILLA; SUCCESSIVE OPERATIONS, WITH IMPROVEMENT ; DEATH EVENTUALIY FROM ERYSIPELAS.

(Under the care of Mr. Cowenu.)

THE following account is derived from the notes of $\mathrm{Mr}_{\text {. }}$ Richard Davy, surgical registrar:-

T. C-, aged fifty-two, a labourer, was admitted on the 22nd of March, 1870. He had presented himself in the outpatient room about two months previously with two prominent symptoms. 1. Pain in the left upper jaw, from which he had suffered for nearly two months, and on account of which two molar teeth had been extracted without relief. 2. Obstruction of both nostrils. There was no enlargement about the cheek or jaw. Mr. Cowell removed some gelatinous polypi from the nose on both sides. Some smart bæmorrhage followed, and some relief to the right nostril, but none to the left. A fortnight later some more mucous polypi were removed, but without any better result. After another two weeks the pain was found to be increasing, and a little fulness was visible in the hard palate on the left side, but still no increase of size in the cheek. This fulness rapidly increased, involving the whole left side of the hard palate, a small portion of the soft palate, and the alveolar processes where the teeth had been removed, and projected downwards into the mouth, as a smooth, firm, globular swelling, through which the two ragged openings of the two teeth appeared. In this condition he was admitted. There was some puffiness of the cheek and lower lid; but no enlargement of the antrum, nor even of the upper part of the superior maxilla. His speech was thickened and 